\title{
Intervention Effect Based on Self-Regulation to Promote the Continuation of Self-Care Behavior of Patients with Type-2 Diabetes Mellitus
}

\author{
Nariko Chuman', Chieko Hatamochi² \\ ${ }^{1}$ Faculty of Health Science, Osaka Aoyama University, Osaka, Japan \\ ${ }^{2}$ Graduate school of Nursing, Osaka Prefecture University, Osaka, Japan \\ Email: n-chuman@osaka-aoyama.ac.jp
}

How to cite this paper: Chuman, N. and Hatamochi, C. (2021) Intervention Effect Based on Self-Regulation to Promote the Continuation of Self-Care Behavior of Patients with Type-2 Diabetes Mellitus. Health, 13, $472-481$.

https://doi.org/10.4236/health.2021.134037

Received: March 3, 2021

Accepted: April 27, 2021

Published: April 30, 2021

Copyright $\odot 2021$ by author(s) and Scientific Research Publishing Inc. This work is licensed under the Creative Commons Attribution International License (CC BY 4.0).

http://creativecommons.org/licenses/by/4.0/

\begin{abstract}
[Purpose] The purpose of this study was to identify the effect of a support program based on self-regulation. [Methods] Participants: Patients with type-2 diabetes mellitus in rural areas; Research design: Quasi-experimental research. A t-test and Mann-Whitney $\mathrm{U}$ test were performed to compare the intervention and control groups before the intervention. For the comparison within the groups before and after the interventions, a t-test and the Wilcoxon signed-rank test were performed. For statistical analysis, the significance level was set to $5 \%$. [Results] The intervention group included 19 participants (age $59.8 \pm 6.14$ ) and 10 participants in the control group (age $64.3 \pm 3.95$ ). After the program, the scores in knowledge about diabetes $(p=0.001)$ and sub-items of the diabetes self-management (foot care) $(p=0.048)$ of the intervention group statistically significantly increased, and the calorie intake decreased $(p=0.080)$. The intervention group had higher scores in all three sub items of the self-efficacy (positiveness, control, and total score). There were no statistically significant differences in the changes in $\mathrm{BMI}, \mathrm{HbA}_{1} \mathrm{c}$, and the subscales of self-efficacy between the two groups. However, the scores of these items of the intervention and control groups were 3.3 and 2.9, 2.2 and -0.3 , and 5.5 and 2.6, respectively. [Conclusions] The support program based on self-regulation in this study helped the participants to acquire general knowledge of diabetes to assess own medical condition and problems in self-care behavior and practical knowledge to manage diabetes in daily life, and this shows the effectiveness of the program.
\end{abstract}

\section{Keywords}

Diabetes Mellitus, Self-Control, Program, Rural Health Services 


\section{Introduction}

The number of patients strongly suspected of having Type-2 diabetes mellitus in Japan reached about 10 million in 2018, and that shows increasing tendency [1]. It has been reported that specialists of secondary medical area are more unevenly distributed than doctors and are not fair to patients who wish to get medical examination by specialists [2].

Therefore, the patients with type-2 diabetes mellitus in rural areas may fail to conduct appropriate self-care without the sufficient access to education provided by professionals.

Self-regulation serves as a guidance for individual patients to achieve own goals and continue self-care behaviors [3], and accurate knowledge promotes the self-care and reduces the emotional burden [4]. For this reason, it may be expected that providing interventions based on self-regulation for patients with type-2 diabetes mellitus in rural areas near urban areas may encourage such patients to continue their self-care. If a support program is developed for areas where diabetes specialists are scarce and the effectiveness of the program is established, the program would enable non-diabetes specialists to provide interventions, and will serve to provide useful suggestions for nursing support in rural areas with few diabetes specialists. Further, there is the significance in the program that is designed for patients to be encouraged to stay motivated to conduct the self-care by themselves.

The purpose of this study is to develop a support program based on self-regulation for patients with type-2 diabetes mellitus in rural areas where medical diabetes specialists are scarce, and to determine the effect of the program.

\section{Research Conceptual Framework}

A previous study has stated that patients with type-2 diabetes mellitus need to manage their diabetes actively, and control their own lives [5]. The conceptual framework of the present study is based on the idea of self-regulation based on the social learning theory of Bandura, which contends that human behavior does not necessarily depend on external reinforcement, but rather is determined by self-reinforcement. Bandura (1986) has also defined that a series of processes formed by self-reinforcement is self-regulation, and stated that human behavior is changed by self-reinforcement.

This present study is structured by the three basic sub processes of self-regulation by Bandura: self-monitoring, self-judgment, and self-reaction. In the conceptual framework of the study, we put the goal before the process of self-monitoring. According to Bandura (1977) [6], learning proceeds when the learner is cognitively motivated, and cognitive motivation arises from the relationship between goal setting and self-control of reinforcement. Bandura (1977) has also stated that self-efficacy plays an important role in predicting actual behavior, and that successful experiences affect self-efficacy. The authors consider that the self-reinforcement process would be further promoted by working on 


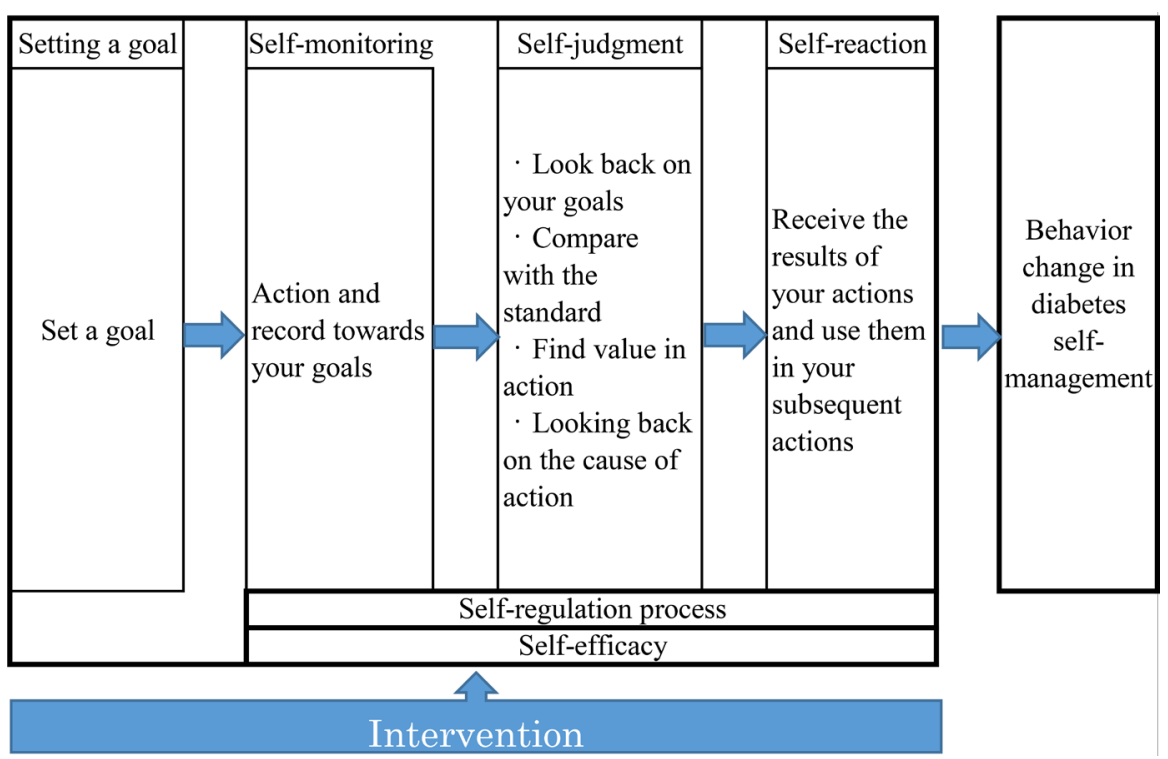

Figure 1. Conceptual framework.

self-efficacy as a support for self-regulation (Figure 1).

\section{Methods}

\subsection{Intervention Method}

\section{Intervention group}

Support program 1: Assistance in setting goals. Before setting the goals, provide explanation using materials that cover basic knowledge of diabetes.

Support program 2: Assist self-monitoring, self-judgment, self-reaction, and self-efficacy related to what efforts patients have made toward their goals. This support is provided during a monthly in-person interview and a telephone interview between the monthly in-person interviews.

1) Self-monitoring: Assign columns in the self-monitoring notebook, where patients can record the efforts they have made toward a goal, daily events, and the factors that hinder the execution of efforts to reach the goal.

2) Goal setting: Explain continuation of self-monitoring toward a goal (progress), to do self-monitoring on a scheduled day, to record the actual doings in self-monitoring within the recent few days, to record efforts patients have made in unique ways (creativity), and explain (ensure accessibility).

3) Self-judgement

- Referenced criteria: Compare the test data of the participating patients with the target data or previous data, and confirm that patients are aware of the differences.

- Value of practice: Inquire from the patients whether they are aware that there is value and significance in the process of making efforts towards a goal, assessing the results, and making use of the results to change their behavior.

- Attributes of cause: Inquire from the patients whether their activities are based on their own will/ideas or determined by others. 
- Self-efficacy: The purpose the self-judgement is to ensure a successful experience. Praise of any action that has been achieved because the successful experience of the goal that is achieved becomes self-efficacy.

- Self-reaction: Involve the patients so that they can continue self-management behavior depending on how they interpret the result of the behaviors. Patient characteristics and self-management status data were collected by a questionnaire survey, and physiological data were collected from medical records.

\section{Control group}

The same teaching materials as intervention group were provided for control group.

For 3 months, regular medical and nursing care were provided, and after 3 months, they were requested to cooperate the same research as the intervention group and the same support program was provided on their request. Physiological data and treatments were collected from medical records.

\subsection{Timing of Interventions}

Interventions in this study are conducted as follows: Request patients to complete a preliminary survey before an intervention. When the survey results are obtained, conduct the first interview and support program 1. Two weeks after introduction to support program 1, contact the patients by phone and conduct support program 2. One month after the first interview, conduct the second interview and support programs 1 and 2 . Two weeks later, contact them by phone and conduct support program 2 . One month after the second interview, conduct the third interview and support program 2. Request the patients to complete a follow-up survey after the support program is over.

\subsection{Data Collection}

Intervention period for each subject was 3 months, but because of individual data collection, it has taken 3 years for total data collection, from November 2010 to October 2013.

\subsection{Surveyed Items and Methods}

Patient characteristics, self-management status and self-efficacy were collected by questionnaires, and physiological data were collected from medical records.

\subsubsection{Patient Characteristics}

1) Demographic characteristics: age, gender, occupation, family living with, diabetes history, economic status.

2) Medical treatment conditions related to diabetes treatment: experience of undergoing diabetes education, details of the treatment, experience of discontinuing treatment, amount of exercise in the previous month.

3) Confirmation of knowledge of diabetes/implementation survey: Created based on the "Diabetes Treatment Handbook". 


\subsubsection{Self-Management Status}

1) Dietary habits: "Simple self-administered dietary history questionnaire" by Sasaki et al. [7].

2) Kinetic momentum: Walking amount.

3) Goal achievement: Goal implementation status described in the self-monitoring notebook.

4) Diabetes self-management status: "Diabetes self-management behavior scale", 22 items were rated on a 4-pont Likert scale (1: never 2: not very often 3: some of the times 4: all of the time) [8].

5) Determination of self-monitoring skills: "Cognitive Behavioral Self-Monitoring Scale”, 17 items were rated on a 5-pont Likert scale (1: totally disagree to 5: totally agree) [9].

6) Self -efficacy: "Chronic disease-self efficacy scale", 24 items were rated on a 4-pont Likert scale (1: totally disagree to 4: totally agree) [10].

7) Physiological data: Body Mass Index (BMI), $\mathrm{HbA}_{1} \mathrm{c}$.

For the $\mathrm{HbA}_{1} \mathrm{c}$ value, the NGSP (National Glycohemoglobin) has been introduced from April of 2012 due to international standardization rules. However, the present study uses the values of the JDS (Japan Diabetes Society) throughout the paper.

\subsection{Methods of Analysis}

The t-test and Mann-Whitney $\mathrm{U}$ test were employed to compare the intervention and control groups before the intervention. For the comparison within groups before and after the interventions, a t-test and the Wilcoxon signed-rank test were performed. The significance level of the statistical analysis set to $5 \%$.

\subsection{Ethical Considerations}

The study was approved by the Institutional Review Board of the Osaka Prefecture University (approval number 21 - 65). Before conducting the research, the researchers explained the study outline to the representatives of each department of participating medical institutions orally and in writing, and obtained the consent to participate in the study. For the participating patients, the researchers detailed the following ethical considerations.

For the intervention group, the researcher explained the study purpose, outline, methods, schedule, that participation is voluntary, that there would be no advantages or disadvantages in the medical treatment and nursing care whether participating or not participating, or discontinuing participation, and that attaching a signature to show informed consent would be regarded as consent to participation, expressed orally and in writing. The researchers also explained the privacy protections for the participants: the data would be handled to ensure anonymity, used only for this study, stored in a secured recording medium, and destroyed with a shredder after presentation of the study results.

For the control group, the researcher explained the study purpose, outline, methods, and schedule orally and in writing, and included the patients who expressed consent to participate in the study. During the intervention period, participants 
continued the regular medical treatment and nursing care. After the final survey activity was completed, individual support programs were provided as desired.

\section{Results}

\subsection{Study Population}

A total of 41 patients were included in the study: 28 for the intervention group, and 13 for the control group. In the intervention group 19 patients completed the three-month program, and those failing to complete were 1 patient due to treatment change, 3 due to worsening chronic diseases, 2 due to dropping out, and 3 due to other reasons. In the control group, 10 patients completed the program, and those failing were 1 due to treatment change, and 2 due to other reasons.

The intervention group included 11 males and 8 females, and the control group had 6 males and 4 females. The mean age of the intervention group was 59.8 years, and that of the controls group 64.3 years (Table 1 ).

\subsection{Changes due to the Interventions}

After the program, the scores in knowledge about diabetes for the intervention and control groups increased by $14.7 \%$ and $1.3 \%$, respectively, showing statistically significant differences between the groups $(p=0.001)$. There was also a statistically significant difference in the item of the diabetes self-management, being able to observe and cleanse own feet and keep regular hours $(p=0.048)$.

In the nutrition survey, the calorie intake decreased by $332 \mathrm{Kcal}$ in the intervention group and $111 \mathrm{Kcal}$ in the control group $(p=0.080)$. There was no significant difference in other items (Table 2).

Table 1. Patient characteristics.

\begin{tabular}{|c|c|c|c|c|c|}
\hline Category & & $\begin{array}{c}\text { Intervention } \\
\text { group }(n=19)\end{array}$ & $\begin{array}{l}\text { Control group } \\
(\mathrm{n}=10)\end{array}$ & $p$ value & \\
\hline Gender (Male/Female) & & $19(11 / 8)$ & $10(6 / 4)$ & 1.000 & $\mathrm{~b}$ \\
\hline Age, $y r \pm S D$ & & $59.8 \pm 6.14$ & $64.3 \pm 3.95$ & $0.048^{\star}$ & a \\
\hline Disease period, $\mathrm{yr} \pm \mathrm{SD}$ & & $8.8 \pm 6.56$ & $12.8 \pm 7.00$ & 0.137 & $\mathrm{a}$ \\
\hline Complications & Yes/No/Unknown & $0 / 10 / 9$ & $1 / 0 / 9$ & - & \\
\hline \multirow[t]{3}{*}{ Treatment } & Diet only & 2 & 0 & - & \\
\hline & Oral medicine & 15 & 10 & - & \\
\hline & Insulin & 2 & 1 & - & \\
\hline Family living with & Yes/No & $15 / 4$ & $8 / 2$ & 0.665 & $\mathrm{~b}$ \\
\hline Occupation & Yes/No & $13 / 6$ & $3 / 7$ & 0.675 & $\mathrm{~b}$ \\
\hline $\begin{array}{l}\text { Experience of receiving } \\
\text { medical treatment life } \\
\text { guidance from a nurse }\end{array}$ & Yes/No & $7 / 12$ & $3 / 7$ & 1.000 & $\mathrm{~b}$ \\
\hline
\end{tabular}

a: t-test, b: Fisher's exact test; ${ }^{\star} \mathrm{p}<0.050$. 
Table 2. Changes in self-management status between the groups.

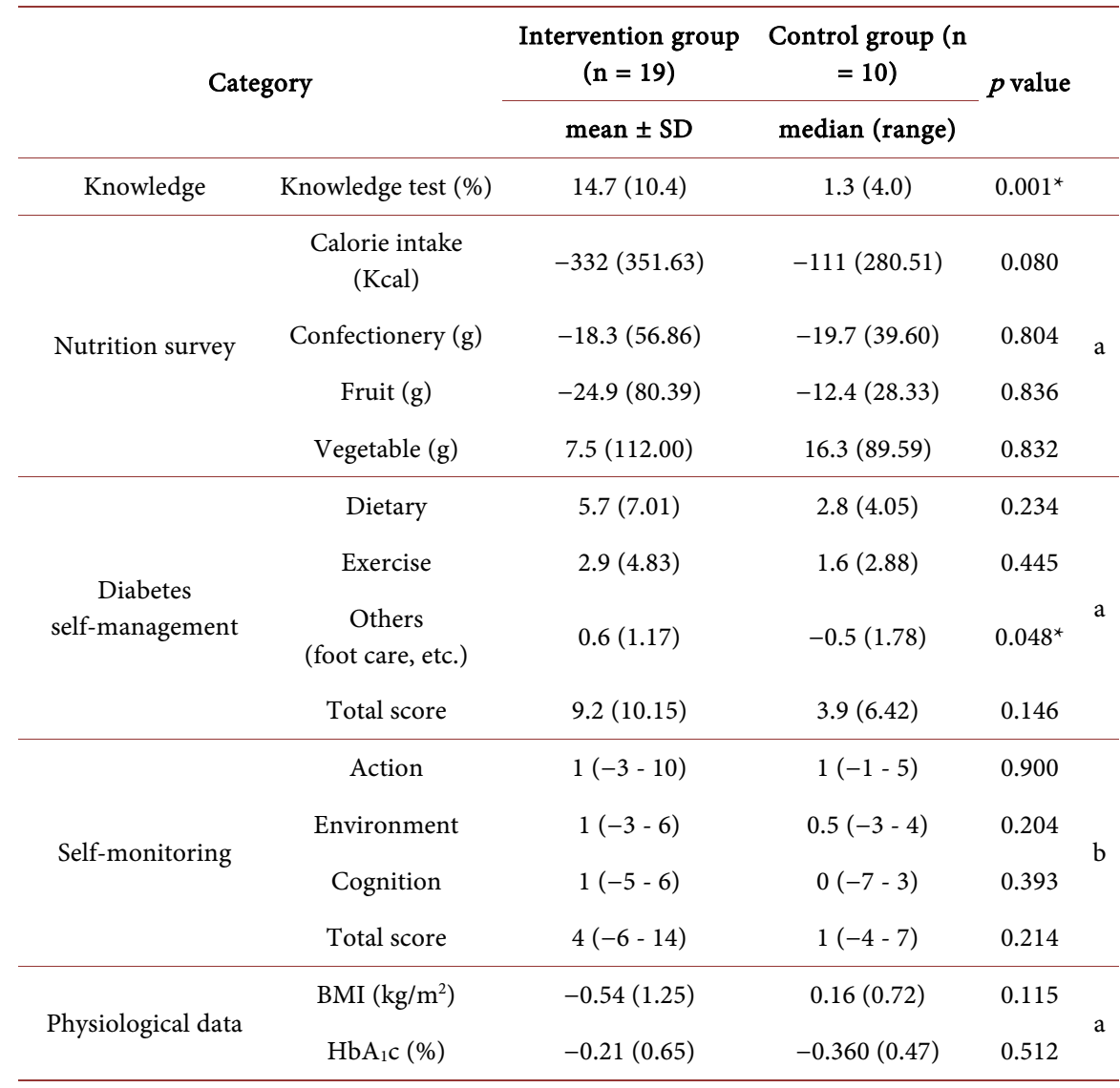

a: $\mathrm{t}$ test; b: Mann-Whitney $\mathrm{U}$ test; ${ }^{\star} p<0.050$.

In the interviews, patients in the intervention group stated that "I had thought I had to do this (self-care behavior), so I did what I had learned. I understand why I have to do self-care because my body weight and $\mathrm{HbA}_{1} \mathrm{c}$ have improved since then" and "I will continue to control meals and do exercises to achieve my goals." After the interventions, patients in the intervention groups came to use their general knowledge of diabetes as practical knowledge to assess their own medical condition and problems in the self-care behavior to manage their diabetes in daily life.

There were no statistically significant differences in the changes in BMI, $\mathrm{HbA}_{1} \mathrm{c}$, and the subscales of self-efficacy between the two groups. However, the intervention group had higher scores in all three sub items of the self-efficacy (positiveness, control, and total score). The scores of these items of the intervention and control groups were 3.3 and 2.9, 2.2 and -0.3, and 5.5 and 2.6, respectively. The comparison within the group before and after the program showed that the intervention group had statistically significant differences, but there were no significant differences for the control group (Table 3).

\section{Discussion}

Goals are set based on knowledge, such as of the required calorie intake, the 
Table 3. Changes in self-efficacy status between the groups.

\begin{tabular}{ccccccc}
\hline \multirow{2}{*}{ Category } & \multicolumn{1}{c}{$\begin{array}{c}\text { Intervention } \\
\text { group }(\mathrm{n}=19)\end{array}$} & $\begin{array}{c}\text { Control group } \\
(\mathrm{n}=10)\end{array}$ & & \multirow{2}{*}{$\boldsymbol{p}$ value } \\
\cline { 3 - 4 } & \multicolumn{2}{c}{ mean \pm SD } & & \\
\hline \multirow{2}{*}{ Self-efficacy } & positiveness & $3.3(5.78)$ & $2.9(4.48)$ & 0.845 & n.s \\
& control & $2.2(4.34)$ & $-0.3(3.47)$ & 0.126 & n.s \\
& Total score & $5.5(8.51)$ & $2.6(7.09)$ & 0.361 & n.s \\
\hline
\end{tabular}

$\mathrm{t}$ test; ${ }^{\star} p<0.050$; n.s: not significant.

amount and method of exercise, and the relationship between blood glucose level, diet, and exercise. The findings suggest that the blood glucose level was stabilized by acquiring knowledge about diabetes and using that knowledge for goal setting and self-management to acquire skills to make own decisions.

The intervention group decreased more in calorie intake than the control group. Previous studies have reported that it is possible to improve dietary behavior by a variety of methods provided by nurses [11] [12] [13] [14]. From the results of the present study, it may also be surmised that calorie intake has improved because the patients themselves conducted the process of self-regulation, they decided to modify their dietary behavior, set own goals, and put these decisions in action.

There were significant differences in the two sub-items of diabetes self management behavior, "being able to observe and cleanse own feet" and "keep regular hours". These are behaviors patients can perform by themselves if they understand the implication of these behaviors. It may be concluded that as the knowledgebase increased, participants improved in the understanding of the effects of these behaviors as a part of the medical treatment.

Self-efficacy was statistically significantly increased in the comparison within the intervention group after the program. Because self-regulation is supported by self-efficacy, increases in self-efficacy could have made it easier for the participants to proceed with the self-efficacy affected process, resulting in the statements that their motivation to conduct self-care increased, and that they would continue the self-care behavior. These results suggest that the intervention had an influence on self-efficacy.

Comparison within the groups before and after the program showed that there was no statistically significant difference in $\mathrm{HbA}_{1} \mathrm{c}$ levels in the intervention group, but there was a significant difference in the control group. In the control group, the baseline $\mathrm{HbA}_{1} \mathrm{c}$ was 7.31, which was higher than that in the intervention group 6.83. Factors associated with the larger improvement in $\mathrm{HbA}_{1} \mathrm{c}$ levels in the control group may be that this group had more room for improvement and that they became more careful about their daily behavior by participating in this study.

Therefore, the researchers expect that this program can be utilized in similar rural areas where there are few diabetes specialists, and that the program will 
make it easier for patients with type-2 diabetes mellitus to continue self-care behavior. However, the findings also suggest the necessity to reconsider the intervention period and develop and improve the contents of and matters taken up in the support program to enable patients in the rural areas to balance self-care behavior and social activities in community, family business, and long-term care.

\section{Limitation and Remaining Issues}

The subjects of this study were the patients with type 2 diabetes who lived in the rural area.

Due to the regional characteristics of the rural area, there was a limit to secure enough number of subjects.

In further study, more than 3 months' intervention period is also required to ensure the acquisition of self-regulation.

\section{Conclusion}

This study developed a support program based on self-regulation for patients with type-2 diabetes mellitus in rural areas with an insufficient number of diabetes specialists. After providing interventions using the program, the scores in knowledge about diabetes for the intervention and control groups increased by $14.7 \%$ and $1.3 \%$, respectively, showing statistically significant differences between the groups $(p=0.001)$. There was also a statistically significant difference in the item of the diabetes self-management, being able to observe and cleanse own feet and keep regular hours $(p=0.048)$.

\section{Conflicts of Interest}

The authors declare no conflicts of interest regarding the publication of this paper.

\section{References}

[1] 2018 National Health and Nutrition Survey Results Summary. Ministry of Health, Labour and Welfare, Tokyo, Japan. (In Japanese) https://www.mhlw.go.jp/stf/houdou/0000177189.html

[2] Horioka, N., Horiguti, I., Sakagami, Y., Marui, E. and Tanigawa, T. (2015) Examination of the Geographical Distribution of Specialists in Japan. Journal of Health and Welfare Statistics, 62, 23-28. (In Japanese)

[3] Maes, S. and Karoly, P. (2005) Self-Regulation Assessment and Intervention in Physical Health And Illness: A Review. Applied Psychology, 54, 267-299. https://doi.org/10.1111/j.1464-0597.2005.00210.x

[4] Watkins, K.W., Klim, L., Connell, C.C. and Hickey, T. (2000) Effect of Adults Self Regulation of Diabetes on Quality-of-Life Outcome. Diabetes Care, 23, 1511-1515. https://doi.org/10.2337/diacare.23.10.1511

[5] Bandura, A. (1986) Social Foundations of Thought \& Action: A Social Cognitive Theory. Prentice Hall, Inc., Upper Saddle River, NJ.

[6] Bandura, A. (1977) Social Learning Theory. Harano, K., Trans., Kaneko Shobo, 
Tokyo, Japan.

[7] Sasaki, S. (2009) Todai Sasaki-Style Dietary Habit Assessment (BHQD/DHQ), Site for Support What Is BHQD? EBN Japan, Tokyo, Japan. (In Japanese)

http://ebnjapan.org/bdhqdhq/

[8] Kinoshita, Y. (1995) Creation of Measuring Tools Related to Self-Management of Diabetes and Examination of Reliability and Validity. Japan Journal of Nursing Science, 15, 39. (In Japanese)

[9] Tsuchida, Y. and Fukushima, O. (2007) Self-Monitoring in Behavioral Coordination-Creation of Cognitive-Behavioral Self-Monitoring Scale. Mejiro University Psychology Research, 3, 85-93. (In Japanese).

[10] Kim, W., Shimada, H. and Sakano, Y. (1996) Relationship between Self-Efficacy and Stress Response to Health Behavior of Patients with Chronic Diseases. Japanese Journal of Psychosomatic Medicine, 36, 499-505. (In Japanese).

[11] Nishikata, K. and Fukuya, S. (2005) Examination of Dietary Performance by Self-Evaluation of Diabetic Patients. The Journal of Japan Academy of Diabetes Education and Nursing, 9, 124-132. (In Japanese)

[12] Usui, R., Kaku, F., Higuchi, T., Naka, S., Kagawa, Y. and Nakagawa, Y. (2007) Approach to Diabetic Patients Using Change Stage Model in General Clinic Outpatient Department. The Journal of Japan Academy of Diabetes Education and Nursing, 11, 177-184. (In Japanese)

[13] Kozai, H., Naruse, Y., Watanabe, K. and Imai, S. (2008) Improvement of Dietary Habits in Patients with Impaired Glucose Tolerance: Effects of Group Education on Self-Management. Journal of Rehabilitation and Health Sciences, 6, 11-15. (In Japanese)

[14] Shiramizu, M., Sugimoto, T., Mase, Y., et al. (2011) Actual Conditions of Diabetes Education Program for Type 2 Diabetic Patients at the Institution to Which a Certified Diabetic Nursing Nurse/Chronic Disease Nursing Specialist Belongs. Journal of Japan Diabetes Education and Nursing Society, 15, 179-187. (In Japanese) 